University of Nebraska - Lincoln

DigitalCommons@University of Nebraska - Lincoln

Architectural Engineering -- Faculty Publications

Architectural Engineering and Construction,

Durham School of

3-2006

Effects of Noise on Productivity: Does Performance Decrease Over Time?

Jessica Errett

University of Nebraska - Lincoln

Erica Eileen Bowden

University of Nebraska - Lincoln

Marc Choiniere

University of Nebraska - Lincoln

Lily M. Wang

University of Nebraska - Lincoln, Iwang4@unl.edu

Follow this and additional works at: https://digitalcommons.unl.edu/archengfacpub

Part of the Architectural Engineering Commons

Errett, Jessica; Bowden, Erica Eileen; Choiniere, Marc; and Wang, Lily M., "Effects of Noise on Productivity: Does Performance Decrease Over Time?" (2006). Architectural Engineering -- Faculty Publications. 13. https://digitalcommons.unl.edu/archengfacpub/13

This Article is brought to you for free and open access by the Architectural Engineering and Construction, Durham School of at DigitalCommons@University of Nebraska - Lincoln. It has been accepted for inclusion in Architectural Engineering -- Faculty Publications by an authorized administrator of DigitalCommons@University of Nebraska Lincoln. 


\title{
Effects of noise on productivity: does performance decrease over time?
}

\author{
Jessica Errett, Erica E. Bowden ${ }^{1}$, Marc Choiniere, and Lily M. Wang
}

Architectural Engineering Program, University of Nebraska - Lincoln, PKI, 1110 S. $67^{\text {th }}$ St., Omaha, NE 68182, USA

${ }^{1}$ corresponding author: PH (402)554-2074; email: ebowden@mail.unomaha.edu

\begin{abstract}
Most people at one time or another have found themselves irritated or distracted by the background noise in a building. The irritation might have resulted in minor aggravation or may have been dramatic enough to hinder their work. This leads us to ask whether occupants are increasingly aggravated by noise the longer they are exposed to it, or if they naturally habituate to their acoustic environment. In an effort to answer this question, a study was completed in the "Indoor Environment Lab" at the University of Nebraska. This lab resembles a typical office and was specially constructed to be acoustically and thermally controlled. Subjects completed 38 total hours of testing in the lab over multiple days, during which time they were exposed to several background noise conditions over 20, 40, 80, and 240 minute trials. During the trials, subjects completed a variety of performance tasks and answered questions about their perception of the noise, the thermal environment and various other factors. End results aid in understanding the prolonged effects of typical heating, ventilating, and air-conditioning (HVAC) noise on worker productivity and annoyance.
\end{abstract}

\section{Introduction}

People encounter noise often in their everyday environments. Noise from heating, ventilating, and air-conditioning (HVAC) systems is typically a major source of background noise in buildings. In offices, HVAC noise can potentially cause annoyance and concentration problems for workers. This has led many in the acoustics community to question how much noise distraction contributes to decreased productivity, and also if the effect changes over time.

There has been a good deal of previous research on how high levels of noise affect productivity (Jones and Broadbent 1998), but much less has been done with typical office background noise. There have been several studies which focus on the effects of excessive low frequency energy in background noise (Kyriakides and Leventhall 1977, Landström et al 1991, Holmberg et al 1993, Persson Waye et al 1997). Some of the conclusions from these studies are that productivity can be affected by background noise, the frequency character of the noise should be considered, and that the impact can potentially change over time. For example, 
Persson Waye et al indicated that ventilation noise dominated by low frequencies could increase the time taken to respond on a verbal reasoning task, when compared with a similar noise of equivalent loudness with much less low frequency energy (1997). Other studies have revealed that people who indicated annoyance with low frequency noise also reported symptoms of fatigue, headaches, and irritation, all of which could lead to decreased on-the-job performance (Tokita 1980, Nagai et al 1989, Persson Waye 2001).

These previous studies were instrumental in establishing that a relationship between noise and worker performance does indeed exist. However, the ways in which background noise truly affects occupants is still not well understood. In particular, there is much debate as to how the length of time an occupant is working under a single background noise condition can impact their performance and perception. Some have hypothesized that occupants become increasingly aggravated by noise the longer they are exposed to it, while others contend that occupants naturally habituate to their acoustic environment. There is additional debate over the types of tests that should be used in research examining the effects of background noise on occupants.

A study was conducted in the "Indoor Environment Lab" at the University of Nebraska to examine these issues. Specifically, the research investigated how HVAC noise impacts task performance and perception over time. Subjects completed testing over multiple days during trials ranging from 20 minutes to four hours. The methodology and preliminary results are discussed in this paper. The study is part of a much larger project examining the ability of indoor noise criteria systems to relate to perception and productivity. Additional details of the larger project are given in another proceeding paper for this conference (Bowden and Wang 2006).

\section{Previous Research on Noise Exposure Time and Types of Tests}

The effects of HVAC noise exposure time has not been widely tested. Previous researchers cited earlier in this paper have used durations ranging from one minute to 60 minutes. Poulson, who studied the annoyance of traffic noise on a listener, suggested that a 5 minute test is long enough to get accurate results (1991). However, indoor HVAC systems-induced background noise may need to be experienced for a longer duration to affect a person's performance.

Another area that required more work concerns the tasks that should be completed by the test subjects. Previously the authors used two self-administered typing and proofreading tasks (Bowden and Wang 2005). Results indicated that a test which requires more cognitive thinking may be necessary for the full effect to emerge. Landström has also discussed this idea (2004). More routine types of tasks indicate if subjects are aroused or paying attention, while more mentally demanding tasks indicate how the subject deals with information overload. Landström has found that information overload tasks are harder under low frequency noise conditions, and that repetitive monotonous tasks may require longer exposures for there to be an effect. 


\section{Methods}

Ten subjects, five male and five female, participated in this study. Each person completed 38 total hours of research testing. Prior to the testing, all subjects were pre-screened for visual and hearing ability. They also completed a short training module to familiarize them with the tests and questionnaires they would be completing in the main portion of the research. Terms on the questionnaires such as "rumbly," "roaring," and "hissy" which are commonly used by architectural acousticians to characterize background noise were demonstrated through sample audio files. More information on these training signals is available in Bowden and Wang $(2005,2006)$.

The experiment was performed in a $25.7 \mathrm{~m}^{3}\left(906 \mathrm{ft}^{3}\right)$ testing chamber, which resembles a typical office. Its measured reverberation time is 0.25 seconds at $500 \mathrm{~Hz}$, and the naturally occurring background noise is low $(<50 \mathrm{~dB}$ from $16 \mathrm{~Hz}$ to $31.5 \mathrm{~Hz}$, $<40 \mathrm{~dB}$ from $63 \mathrm{~Hz}$ to $500 \mathrm{~Hz}$, and $<30 \mathrm{~dB}$ from $1 \mathrm{kHz}$ to $8 \mathrm{kHz}$ ). Both the temperature and lighting were maintained at a reasonably constant level. Noise exposures were presented over two loudspeakers: an overhead panel loudspeaker resembling a ceiling tile and a subwoofer disguised as an end-table in the corner. Neither was easily identifiable as a loudspeaker.

Six different noise conditions were tested under four different time durations. The six noise conditions used were:

(1) Low-level neutral condition: broadband noise, simulated with $-5 \mathrm{~dB} /$ octave band slope, intersecting $30 \mathrm{~dB}$ at $1000 \mathrm{~Hz}$

(2) Mid-level neutral condition: broadband noise, simulated with -5 $\mathrm{dB} /$ octave band slope, intersecting $40 \mathrm{~dB}$ at $1000 \mathrm{~Hz}$

(3) Mid-level rumbly condition: broadband noise, simulated with $-5 \mathrm{~dB} /$ octave band slope, intersecting $40 \mathrm{~dB}$ at $1000 \mathrm{~Hz}$, and with the level in the low frequency octave bands $(31.5 \mathrm{~Hz}$ and $63 \mathrm{~Hz})$ increased by 5 to $10 \mathrm{~dB}$ (4) Steady-state tonal condition: broadband noise with a tonal component at $120 \mathrm{~Hz}$, with the overall level equalized to $49 \mathrm{~dB} \mathrm{~L}_{\text {Aeq }}$ (ISO 226 1987)

(5) Fluctuating tonal condition: broadband noise with a tonal component at $200 \mathrm{~Hz}$, with the overall level equalized to $48 \mathrm{~dB} \mathrm{~L}_{\text {Aeq }}$

(6) Low frequency fluctuating condition: broadband noise whose lowfrequency components exhibit amplitude modulated/frequency modulated (AM/FM) characteristics, with the overall level equalized to $41 \mathrm{~dB} \mathrm{~L}_{\text {Aeq }}$

The first three noise conditions are repeated from a previous study conducted by Bowden and Wang (2005). Signals one and two were intended to sound perceptually "neutral" to subjects; that is, spectrally balanced and devoid of excessive low, mid, or high frequency energy. A primary difference between these two signals was that signal 2 was louder than signal 1. Condition 3 was intended to sound "rumbly," meaning it contained elevated low frequency energy. Conditions four through six were recordings made by ASHRAE Technical Committee 2.6 members, which were then calibrated in the test chamber to very closely match levels measured in the real-life spaces. 
Subjects were exposed to each of the six background noise exposures over 20, 40,80 , and 240 minute trials. One or more trials were combined into several sessions, which lasted for either two or four hours (see Table 1). The maximum exposure time of 4 hours was selected because it corresponds to roughly half of a typical working day. It was anticipated that this is the longest amount of time that the average office worker would carry on without a restroom or meal break. The end result was 38 total hours of testing per subject over multiple testing days.

Table 1 - Format of test sessions for each noise exposure length

\begin{tabular}{|c|c|c|c|c|}
\hline $\begin{array}{c}\text { Noise } \\
\text { Exposure } \\
\text { Length } \\
(=\mathbf{A})\end{array}$ & $\begin{array}{c}\text { \# of Noise } \\
\text { Conditions } \\
\text { per Session } \\
(=\mathbf{B})\end{array}$ & $\begin{array}{c}\text { Length of } \\
\text { One Test } \\
\text { Session } \\
(=\mathbf{C}=\mathbf{A} * \mathbf{B})\end{array}$ & $\begin{array}{c}\text { Number of } \\
\text { Sessions } \\
\text { Required for 6 } \\
\text { Noise } \\
\text { Conditions } \\
(=\mathbf{D}=\mathbf{6} * \mathbf{A} / \mathbf{C})\end{array}$ & $\begin{array}{c}\text { Subtotal of } \\
\text { Testing } \\
\text { Time } \\
\text { Required } \\
(=\mathbf{E}=\mathbf{C} * \mathbf{D})\end{array}$ \\
\hline \hline 20 minutes & 6 & 120 minutes & 1 & 2 hours \\
\hline 40 minutes & 3 & 120 minutes & 2 & 4 hours \\
\hline 80 minutes & 3 & 240 minutes & 2 & 8 hours \\
\hline 240 minutes & 1 & 240 minutes & 6 & 24 hours \\
\hline & & TOTAL TESTING TIME $=$ & $\mathbf{3 8}$ hours \\
\hline
\end{tabular}

During each noise exposure, the test subject completed three different types of computer-based performance tasks. Math and verbal reasoning tests fall under information overload theory (mentally challenging tasks), while typing tests are more related to arousal theory (routine tasks).

The math test consisted of simple math statements and short word problems (SkillCheck 2005). The problem difficulty levels ranged from easy to hard, and the subject was allowed to use paper and pencil to assist his/her work.

The verbal reasoning tests were comprised of true or false questions that dealt with order of letter combinations (Baddeley 1968). These questions also ranged in difficulty level. An example question is: AB: A is before B. True or false?

Finally, during the typing test, the subject would use the computer to retype a paragraph that was seen on piece of paper in beside him/her (SkillCheck 2005). The subject had 5 minutes to accurately type as much of the paragraph as possible.

Periodically throughout the testing, subjects completed surveys to answer questions about their perception of the noise, the thermal environment, lighting levels, and comfort of their workstation. Recall that the only factor changing was the noise; temperature, lighting, etc. were all controlled to be relatively constant. The noise 
questions asked specifically about loudness, rumble, roar, hiss, tonality, timevariance, distraction, and annoyance.

The order of noise exposures, test material, and time durations was randomized for each test subject. All versions of the tests were carefully developed to be equivalently difficult. For example, version 1 of the math test was as difficult as version 2 , etc.

\section{Preliminary Results}

Pearson Product Moment Correlations ( $r$ ) were calculated to assess the relationships between the performance test scores, subjective ratings of noise, and time length of exposure (Field and Hole 2003). The correlation coefficients quantify the strength of the relationship between two variables. Additional statistical methods are currently being investigated. This paper highlights some of the results.

\section{Exposure Time Results}

No significant correlations were found between the time length of exposure and the performance task scores. An example is given in Figure 1, which shows the average scores on the reasoning tests over time. The scores shown in Figure 1 are averaged over all test subjects. In general, the change in the average scores over time is minimal. Other noise conditions exhibited more erratic changes over time.

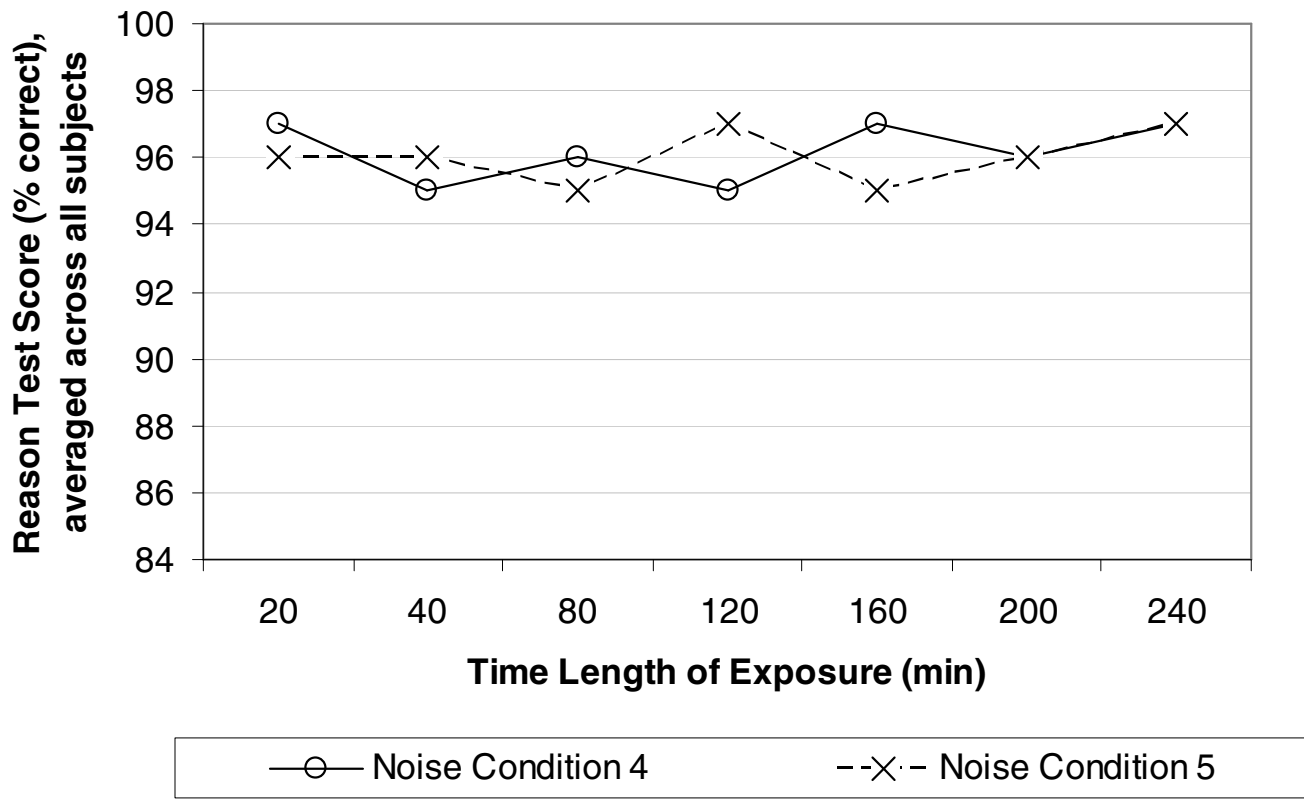

Figure 1 -Time length of exposure ( $\mathrm{min}$ ) versus the reasoning task scores for noise conditions 4 and 5 . All scores shown are averaged across all subjects.

Although the length of exposure did not seem to be strongly related to worker performance, there was some evidence that subjects found the background noise to be louder and more hissy earlier in time $(p<0.05)$. It is possible that the 20 minute 
exposures allowed for more comparison between back-to-back noise signals, thereby affecting the results. Times of 60 minutes are being used in on-going research, with subjects only hearing one noise condition per testing day. It is felt that exposing subjects to only one condition will more accurately reflect their "true" feelings about a particular background noise.

It was also observed that performance on the reasoning tests was higher than on the math tests overall, which was expected because of the general difference in difficulty of the two tasks. It appeared that the three types of tests used in this study may be equally effective, although this is still under investigation. Specifically, the authors are determining if differences between the tests relate in any way to exposure length and signal type. On-going research continues to use all three types of tasks.

\section{Relating Perception to Performance}

Despite the fact that exposure time was not shown to significantly impact performance, there was an indication that perception of the background noise did impact performance. For example, scores on the typing, math, and verbal reasoning tests tended to decrease when subjects were more annoyed by the noise. Perception of spectral imbalance, such as rumble, roar, and hiss, were also shown to impact performance. This is demonstrated in Figure 2, where performance on the math test decreased when subjects perceived noise to be more hissy $(p<0.05)$. These findings support the idea that a more neutral-sounding spectrum is desirable in working environments.

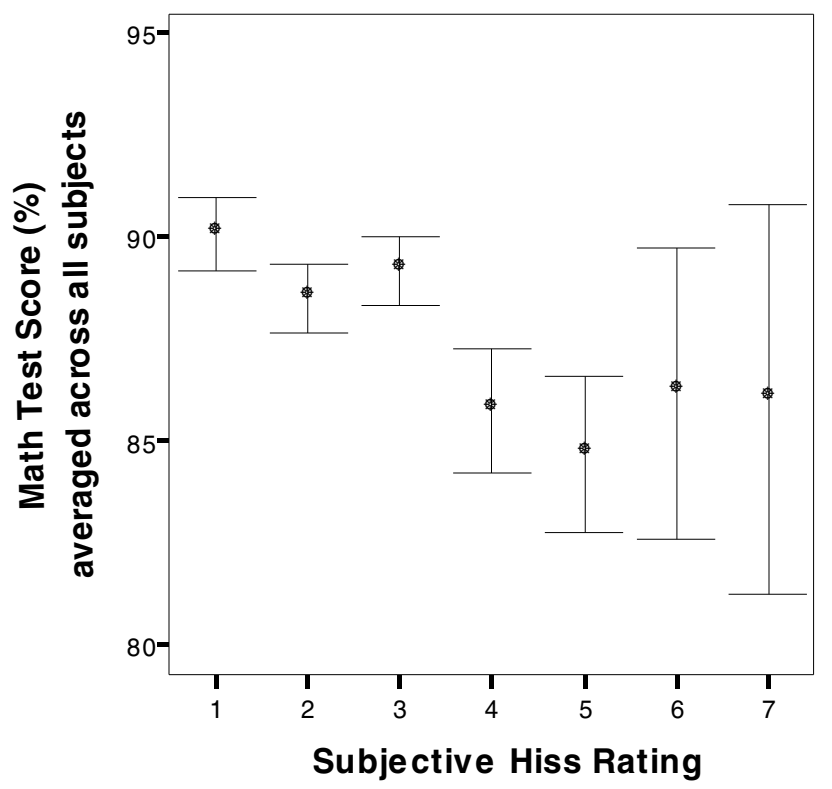

Figure 2 - Subjective hiss ratings versus math test score (\% correct) averaged across all subjects and noise conditions. Standard error bars are shown. The hiss rating scale ranges from $1=$ not hissy to 7 = very hissy. 


\section{Summary}

The overall goal of this study was to determine how time length of exposure to background noise and the types of tests used in research of this nature can impact the results. Ten subjects completed performance tasks and perception questionnaires under six different HVAC noise conditions. Subjects were exposed to each of the six noise conditions for 20, 40, 80, and 240 minute trials. Math, verbal reasoning, and typing tests were used. Preliminary findings indicate that exposure time did not have a significant effect on performance, but subjects tended to rate signals as louder and more hissy earlier in time. It was also found that perception of noise can impact performance. The authors are currently investigating how the results are related to the types of noise conditions included. Overall results are being used to refine testing methodology for on-going tonal and fluctuating noise studies evaluating indoor noise criteria systems.

\section{Acknowledgements}

This work has been supported by the American Society of Heating, Refrigerating, and Air-Conditioning Engineers (ASHRAE), the Institute of Noise Control Engineering (INCE), and the University of Nebraska - Lincoln Center for Building Integration. The authors are grateful for the recording contributions of Warren Blazier, Norman Broner, Mark Fly, Mark Schaffer, and Jerry Lilly.

\section{References}

Baddeley, A.D. (1968). "A 3 min reasoning task based on grammatical transformation." Psychonomic Science, 10, 341-342.

Bowden, E.E., and Wang, L.M. (2005). "Relating human productivity and annoyance to indoor noise criteria systems: a low frequency analysis." The 2005 ASHRAE Winter Meeting Transactions, Orlando, 111, pt. 1, 684-692.

Bowden, E.E., and Wang, L.M. (2006). "Appropriate characterization of background noise levels in the workplace." Proceedings of the 2006 Architectural Engineering Institute Conference, Omaha, NE.

Field, A., and Hole, G. (2003). How to Design and Report Experiments, Sage Publications, London.

Holmberg, K., Landström, U., and Kjellberg, A. (1993). "Effects of ventilation noise due to frequency characteristic and sound level." J. Low Freq. Noise Vib., 16, 115-122.

Jones, D., and Broadbent, D. (1998). "Human Performance and Noise." in Handbook of Acoustical Measurements and Noise Control, edited by C. Harris, Acoustical Society of America, Melville, NY, Chap. 24, pp. 24.1 - 24.24.

Kyriakides, K., and Leventhall, H.G. (1977). "Some effects of infrasound on task performance." J. Sound Vib., 50(3), 369-388.

Landström, U. (2004). "Ventilation noise and its effects on annoyance and performance." J. Acoust. Soc. Am., 115(5), 2370(A). 
Landström, U., Kjellberg, A., Söderberg, L., and Nordström, B. (1991). "The effects of broadband, tonal, and masked ventilation noise on performance, wakefulness and annoyance." J. Low Freq. Noise Vib., 10, 112-122.

Nagai, N., Matsumoto, M., Yamasumi, Y., Shiraishi, T., Nishimura, K. Matsumoto, K., Miyashita, K., and Takeda, S. (1989). "Process and emergence on the effects of infrasonic and low frequency noise on inhabitants." J. Low Freq. Noise Vib., 8, 87-99.

Persson Waye, K. (2001). "The prevalence of annoyance and effects after long term exposure to low frequency noise." J. Sound Vib., 240, 483-497.

Persson Waye, K., Rylander, R., Benton, S., and Leventhall, H.G. (1997). "Effects on performance and work quality due to low frequency ventilation noise." $J$. Sound Vib., 205, 467-474.

Poulson, T. (1991). "Influence of session length on judged annoyance." J. Sound Vib., 145(2), 217-224.

SkillCheck ${ }^{\mathrm{TM}}$ Corporation. (2005). http://www.skillcheck.com.

Tokita, Y. (1980). "Low frequency noise pollution problems in Japan." Proceedings of the Conference on Low Frequency Noise and Hearing, Aalborg, Denmark, 189-196. 